\title{
UN VESTIGIO DESCONOCIDO DE TIERRA SANTA: LA VERA CREU D'ANGLESOLA'
}

\author{
NIKOLAS JASPERT \\ Universität Erlangen-Nürnberg \\ (Alemania)
}

Desde hace muchos siglos, la iglesia parroquial de Anglesola, situada ochenta kilómetros al este de Lleida, conserva en el interior de un reliciario altomedieval ocho fragmentos de la Vera Cruz, encontrándose todo ello en una cruz dorada del siglo $\mathrm{XVII}^{2}$. Les santes virtuts, nombre con él que son conocidas las reliquias por los feligreses, han sobrevivido, aunque en un estado algo deteriorado, a las muchas vicisitudes que ha experimentado la iglesia, entre ellas varios intentos de robo $^{3}$. Ni las partículas ni la cruz exterior serán objeto de este estudio, solo el relicario románico interior (fig. $1,2$ y 3$)^{4}$. Esta estauroteca -o relicario de la Vera Cruz de doble travesa-

'Recordando las conversaciones que mantuve en su día con Regina Sáinz de la Maza, quisiera dedicar este artículo a la memoria de la compañera que tanta hospitalidad mostró a los jóvenes historiadores forasteros en Barcelona.

'Josep Binefa I Monjo, Anglesola i la Santa Creu, Solsona, 1964: Antoni BaCH I RIU. Història d'Anglesola, Barcelona, 1987, pp. 51-53: Josep BINEFA I MONJO, El senyoril d'Anglesola en la Cataluny'a medieval. Selecció de textos inédits, "Urtx", 4 (1992), pp. 31-47; La descripción en Catalunya Romànica XXIV: El Segrià, les Garrigues, el Pla d'Urgell, la Segarra, L'Urgell, Barcelona, 1997, pp. 521-522, es insatisfactoria y en parte errónea.

${ }^{3}$ Binefa, Anglesola, pp. 22-23, 53.

${ }^{4}$ Quisiera dar las gracias a Dr. T. Frank (Berlin), Dr. F. López Alsina (Santiago de Compostela), Mn. Prat (Anglesola), y M. Sucarrat Sabaté (Barcelona) por la ayuda prestada en conseguir las fotografías.

"Anuario de Estudios Medievales". 29 (1999) 
ño- mide 18 centímetros de altura y tiene una anchura de 12 y 8,5 centímetros en el travesaño superior e inferior respectivamente. Está formado por un cuerpo de madera cubierto con dos finas láminas de plata adornadas con medallones y círculos estampados. En los nudos de los travesaños se abren dos ranuras en forma de cruz griega donde se encuentran los fragmentos de la Vera Cruz. La ranura inferior fue gravemente dañada durante la Guerra Civil y posteriormente restaurada de forma deficiente (fig. 2 y 3). Alrededor de la cruz superior se agrupan cuatro clípeos con representaciones estampadas de las figuras del Tetramorfos, los signos de los evangelistas, y al lado de la cruz inferior dos rosetas cuadrilóbulos ciegas flanqueadas a su vez por dos medallones con sendas imágenes de ángeles. La parte inferior del palo vertical está adornada con tres clípeos, dos con variadas hojas y uno con una figura barbuda, una roseta y la representación deteriorada de una cúpula coronada por una cruz griega. La línea perlada que bordea el anverso queda apenas visible a causa de la orla de plata añadida toscamente en una época posterior, y que sirve como fijación de las dos caras. El dorso de la estauroteca lleva la Dextera Domini, la mano de Dios, en la parte superior del vástago vertical, seguida en el nudo del travesaño superior por un medallón con una paloma flanqueada por dos ángeles que señalan hacia la misma. Tanto el travesaño inferior como el palo vertical están adornados con róleos vegetales multiformes, intercalados -en el centro y los extremos del mismo- por un medallón con el Agnus Dei y dos ángeles similares a los del vástago superior. Casi al pie del palo central se distingue otro ángel. La obra es de una técnica relativamente sencilla, basada en el prensado con troqueles, y de un estilo que los estudiosos locales han calificado de "bizantino"s. Esta atribución y la falta de estudios detallados suscita la pregunta sobre el origen de la Vera Creu d'Anglesola.

Según una fuente del siglo XVIII, el llibre de confraries de Anglesola, fue un ángel en forma de un peregrino llamado Martino de Monte Sancto, quien trajo las astillas a Cataluña a comienzos del siglo $\mathrm{XIII}^{6}$. Al

'BACH, Història d'Anglesola, p. 52. Cf. Sobre los contactos entre Bizancio y la Península: David WASSERSTEIN, Byzantium and Al-Andalus, "Mediterranean Historical Review", 2 (1987), pp. 76-101; Krijna Nelly CiggaAR, Western Travellers to Constantinople: the West and Byzantium 962-1204. Cultural and Political Relations. Medieval Mediterranean 10, Leiden, 1996, pp. 295-321.

'Anglesola, Arxiu Parroquial, Llibre de Confraries; cf. BINEFA, Anglesola, pp. 20-21. Véase las leyendas paralelas sobre la Vera Cruz en Polonia: Marek DERWICH, Zur Translation der Heilig-Kreuz-Reliquie auf dem Berg Lysiec. Genese, Fortentwicklung und Pragmatik einer 
caer enfermo éste fue admitido en el hospital que la orden de los trinitarios tenía en Anglesola ${ }^{7}$, y antes de morir dejó las reliquias a los fratres como recompensa por los buenos servicios que le habían prestado. Las primeras referencias documentales sobre la reliquia y la capilla donde fue guardada datan de la segunda mitad del siglo XIV ${ }^{8}$. Los habitantes del pueblo dieron por seguro, que su reliquia incluso tenía poder para interceder ante Dios contra los elementos, ya que en 1362 los prohoms de Anglesola llegaron a un acuerdo con el rector de la iglesia parroquial para que uno de los clérigos subiera al campanario de la iglesia con el lignum crucis cada vez que el mal tiempo se acercara". Una serie de píos legados demuestran la devoción de que gozó durante toda la baja Edad Media ${ }^{10}$.

Las raíces de la devoción a la Vera Cruz tanto en Cataluña como en el resto de la Península Ibérica son mucho más antiguas. Basta recordar las cruces-relicarios de Oviedo o los himnos hispanos en honor a la Vera Cruz para percatarse de una larga tradición en el oeste de la Península". Según un ritual asturleonés del siglo XI, ya desde tiempos visigodos una reliquia del lignum crucis era llevada delante del ejercito cristiano cuando éste partía a la guerra ${ }^{12}$. La devoción a la Vera Cruz no fue menos intensa al este de

spätmittelalterlichen Klosterlegende, "De ordine vitae. $\mathrm{Zu}$ Normvorstellungen, Organisationsformen und Schriftgebrauch im mittelalterlichen Ordenswesen", ed. Gert MELVILLE, Vita Regularis 1, Münster, 1996, pp. 381-402.

${ }^{7}$ Joaquím Miret I SANS, Les cases de templers $i$ hospitalers en Cataluny'a. Aplech de noves i documents historichs, Barcelona, 1910, pp. 58-59; BINEFA, Anglesola, pp. 14-15: BACH, Història d'Anglesola, pp. 93-94.

${ }^{8}$ Binefa, Anglesola, pp. 25-27.

"Anglesola, Arxiu Parroquial, Llibre del Curat I, p. 236: cf. BINEFA, Anglesola, 23-24. Esta costumbre persistió hasta los tiempos modernos (ibidem).

${ }^{10}$ Binefa, Anglesola, p. 25.

"Joseph SzÖvÉRFFY, "Crux fidelis" Prologomena to a History of the Holy Cross Hymns, "Traditio" 22 (1966), pp. 1-41, especialmente pp. 14-17; Helmut SCHLunK, Las cruces de Oviedo. El culto a la Vera Cruz en el Reino Asturiano, Oviedo, 1985; Carlos CID PRIEGO, Las narraciones en torno a las dos cruces prerománicas asturianas, Príncipe de Viana 51 (1991) pp. 57-82; Soledad SUÁREZ BELTRÁN, Los orígenes y la expansión del culto a las reliquias de San Salvador de Oviedo. "Las peregrinaciones a Santiago de Compostela y San Salvador de Oviedo en la Edad Media, actas del Congreso Internacional celebrado en Oviedo 1990“, Oviedo, 1993), pp. 37-55; María Josefa SANZ FUENTES, Documentos pontificios medievales referentes al jubileo ovetense de la Santa Cruz, "Forschungen zur Reichs-, Papst- und Landesgeschichte: Peter Herde zum 65. Geburtstag von Freunden, Schülern und Kollegen dargebracht“, 2 vols., ed. Karl BORCHARDT/ Enno BÜNZ, Stuttgart 1998, I, pp. 783-795.

'Charles KOHLER, Translation de reliques de Jérusalem à Oviedo, "Revue de l'Orient latin", 5 (1897), pp. 1-21; Marius FÉROTIN, Le "Liber Ordinum" en usage dans l'Eglise wisigothique et mozarabe d'Espagne du cinquième au oncième siècle, Paris, 1904, c. 149-153: 
la Península ${ }^{13}$. También aquí encontramos reliquias como las de Bagà y Riells de $\mathrm{Fai}^{14}$, así como advocaciones como la de la misma catedral de Barcelona. Estas manifestaciones se enmarcaban dentro de dos corrientes de religiosidad popular altomedieval: el incremento del culto a las reliquias ${ }^{15}$ y la nueva devoción jerosolimitana ${ }^{16}$. La devoción hacia la Ciudad Santa alcanzó todos los países de la cristiandad latina y se intensificó por el cristocentrismo de los siglos XI y XII ${ }^{17}$. La devoción a la Cruz, y en

José GoÑi Gaztambide, Historia de la Bula de la Cruzada en España, Victoriensia. Publicaciones del seminario de Vitoria 4, Vitoria, 1958, pp. 33-34; Claudio SÁNCHEZALBORNOZ, El ejército y la guerra en el reino asturleonés, 718-1037, "Ordinamenti militari in occidente nell'alto medioevo", 15 Settimana di studio del centro italiano di studi sull'alto medioevo, Spoleto 1968, pp. 298-428, especialmente pp. 422-423.

${ }^{13}$ Para otros ejemplos altomedievales véase Anatole Frolow, La relique de la Vraie Croix. Recherches sur le développement d'un culte, "Archives de l'Orient Chrétien", 7, Paris, 1961, pp. $280,337,416$.

${ }^{14}$ Josep Gudiol I CUNILl, Las creus d'argenteria a Catalunya, "Anuari d'Estudis Catalans", 6 (1919-20), pp. 265-422, especialmente pp. 270-271, 331: Cataluny'a Románica XII: El Berguedì. Barcelona 1985, pp. 117-120.

${ }^{15} \mathrm{~J}$ oseph BraUn, Die Reliquiare des christlichen Kultes und ihre Entstehung, Freiburg i.Br., 1940; Marie-Madeleine GAUTHIER, Les routes de la foi Reliques et reliquaires de Jérusalem à Compostelle, Paris, 1983: Franco CARDINI, Reliquie e pellegrinaggi, "Santi e demoni nell'Alto Medioevo (secoli V-XI)“, 36 Settimana di studio del centro internazionale, Spoleto, 1989, pp. 981-1037; Bernhard TÖPFER, The Cult of Relics and Pilgrimage in Burgundy and Aquitaine at the Time of the Monastic Reform, "The Peace of God", ed. Thomas HEAD/ Richard LANDES, Ithaca, 1992, pp. 41-57; Arnold ANGENENDT, Heilige und Reliquien. Die Geschichte ihres Kultes vom frühen Christentum bis zur Gegenwart, München, 1994, pp. 149-166; Anton LEGNER, Reliquien in Kunst und Kultur, zwischen Antike und Aufklärung, Darmstadt, 1995; Anna BENVENUTI, Reliques et surnaturel au temps des croisades, "Les Croisades. L'Orient et l'Occident d'Urbain II à Saint Louis 1096-1270“, ed. Monique REY-DELQUÉ, Milano, 1997. pp. 355-361; Daniel ThURRE, Les reliquaires alu temps des croisades d'Urbain II à saint Louis (1096-1270), “Les Croisades. L'Orient et l'Occident d'Urbain II à Saint Louis 1096-1270“, ed. Monique REY-DELQUÉ, Milano, 1997, pp. 362-367.

${ }^{16}$ Franz NIEHOFF, Umbilicus Mundi-Der Nabel der Welt. Jerusalem und das Heilige Grab) im Spiegel von Pilgerberichten und-karten, Kreuzzügen und Reliquiaren, "Ornamenta ecclesiae", 3 vols., ed. Anton LeGner, Köln, 1985, III, 53 - 72; Alphonse DuPRONT, Le Sacré. Croisades et pèlerinages, images et langages, Paris, 1987, pp. 146-162; Franco CARDINI, Gerusalemme d'oro, d'argento e di luce: pellegrini, crociati, sognatori d'Oriente fra XI e XV secolo, Milano, 1991, pp. 154-204; Ferdinando MolTENI, Memoria Christi. Reliquie di Terra Santa in Occidente, Firenze, 1996; Aryeh Graboïs, Le pèlerin occidental en Terre sainte au Moyen Age, Paris-Bruxelles, 1998, pp. 59-67, 76-81; Kaspar ELM, "Umbilicus Mundi". Beiträge zur Geschichte Jerusalems, der Kreuzzüge, des Ordens der regulierten Chorherren v'om Hlg. Grab und der Ritterorden, Bruges, 1998.

${ }^{17}$ Johannes Laudage, Priesterbild und Reformpapsttum im 11. Jahrhundert, Beihefte zum Archiv für Kulturgeschichte 22, Köln - Wien, 1984; Jean Châtillon, The Spiritual Rencissance of the End of the Eleventh Century and the Beginning of the Twelfth, "The American Benedictine Review“, 36 (1985), pp. 292-317; Giles Constable, Three Studies in Mediev'al Religious and Social Thought, Cambridge, 1995; pp. 143-248, especialmente pp. 199-217; Giles CONSTABLE, The Reformation of the Twelfth Century, Cambridge, 1996, pp. 278-282. 
particular a la Vera Cruz, que se expresó en centenares de reliquias y relicarios medievales del lignum crucis en todos los países de la cristiandad latina y griega tan sólo fue una manifestación de la misma ${ }^{18}$. Ya antes de la Primera cruzada existía una serie de iglesias dedicadas al Santo Sepulcro en Cataluña, y su número aumentó después de la conquista de 1099. Dramas paralitúrgicos celebraron no solo los hechos, sino también los lugares del nuevo testamento, y las reliquias del Santo Sepulcro proliferaron en el este de la Península ${ }^{19}$. En este marco general se sitúan las reliquias hispanas de la Vera Cruz. En muy pocos casos tenemos noticias de su origen, pero por regla general éste se situaba o en Constantinopla o en Jerusalén. Fue en la Ciudad Santa donde se cree que la emperatriz Elena encontró un gran trozo de la cruz $^{20}$. Mientras que una parte quedó allí, donde fue dividida y escondida cuando la ciudad cayó en manos musulmanas, otra fue enviada a Constantinopla, donde se acumuló un verdadero tesoro de tales reliquias, acabando muchas de ellas en Occidente como consecuencia de la toma de esta ciudad por los cruzados en $1204^{21}$. En cambio, la mayor parte de las

\footnotetext{
${ }^{18}$ Etienne Delaruele, Le cruxifix dans la piété populaire et dans l'art, du $V I^{\prime}$ au XI siècle, "Etudes ligériennes d'histoire et d'archéologie médiévales, ed. René LouIS, Auxerre, 1975, pp. 133-144; CARDINI, Reliquie e pellegrinaggi, pp. 1003-1027; CONSTABLE, Three Studies, pp. 210-217. Véase la recopilación extensa, pero de ningún modo completa de Anatole Frolow (Frolow, Relique), que abarca 1150 piezas, y Anatole Frolow, Les reliquaires de la Vraie Croix, "Archives de l'Orient Latin 8", Paris, 1965. Sobre el origen bizantino de las estaurotecas véase: Bianca KüHNEL, Crusader Art in the Twelfth Century. A Geographical, an Historical, or an Art Historical Notion?, Berlin, 1994, 138-140; LEGNER, Reliquien in Kunst und Kultur, pp. 55-78.

${ }^{19}$ Nikolas JASPERT, Stift und Stadt. Das Heiliggrabpriorat von Santa Anna und das Regularkanonikerstift Santa Eulàlia del Camp im mittelalterlichen Barcelona, 1145-1423. Berliner historische Studien 24, Ordensstudien X, Berlin, 1996, pp. 116-123.

${ }^{20} \mathrm{Henri}$ LECLERCQ, Croix (invention et exaltation de la vraie), "Dictionnaire d'archéologie chrétienne et de liturgie" vol. III/2. Paris, 1948, c. 3131-3139; Stephan BORGEHAMMER, How" the Holy Cross was found. Bibliotheca Theologicae Practicae 47, Stockholm, 1991: Jan Willem DRIYVERS, Helena Augusta: the Mother of Constantine the Great and the Legend of the Finding of the True Cross, Leiden, 1992.

${ }^{21}$ Carlo CECCHELl, Il trionfo della croce. La croce e $i$ santi segni prima e dopo Constantino, Roma, 1954, pp. 171-174; Heinrich A. DRAKE, Eusebius on the True Cross, "Journal of Ecclesiastical History", 36 (1985), pp. 1-22; Giuseppe LIGATO, The Political Meanings of the Relics of the Holy Cross among the Crusaders and in the Latin Kingdom of Jerusalem: an example of 1185, "Autour de la Première Croisade. Actes du Colloque de la Society for the Study of the Crusades and the Latin East". Clermont-Ferrand, 22-25 juin 1995. Paris, 1996, pp. 315-330, p. 316, nota 3. Sobre las reliquias de Constantinopla véase: Paul RIANT, Exuviae sacrae constantinopolitanae, II, Genève 1878; Jean EBERSHOLT, Orient et Occident, recherches sur les anciens trésors des églises de Constantinople, Paris 1929; Frolow, Relique, pp. 301-305; Gauthier, Routes de la foi, pp. 66-82; Marie-Madelaine GAUTHIER, Reliquaires du XIIIe siècle entre le Proche Orient et l'Occident latin, "Il Medio Oriente e
} 
reliquias occidentales del lignum crucis del siglo XII fue atribuida a la Palestina recientemente conquistada por los cruzados.

Pocas semanas después de la toma de la Ciudad Santa, el día 5 de Agosto de 1099, una parte de la Vera Cruz fue redescubierta ${ }^{22}$. Rápidamente se convirtió en la reliquia más importante del joven reino de Jerusalén, en el símbolo de los estados cruzados y en su tesoro más preciado ${ }^{23}$. Ya en el año de su descubrimiento, la reliquia fue portada en la batalla contra los musulmanes para elevar la moral de los combatientes cristianos, y durante las ocho décadas hasta el fín del reino cruzado de Jerusalén, volvió a salir de la Ciudad Santa en más de treinta ocasiones, convirtiéndose así en la insignia del reino en tiempos de peligro inminente ${ }^{24}$. Al igual que a la reliquia catalana al lignum crucis jerosolimitano se le reconocía el poder de conseguir la intercesión divina contra los elementos ${ }^{25}$. Pero al contrario de otras reliquias de la Vera Cruz, la de Jerusalén también tuvo una considerable importancia política. Fue el punto de cristalización de la casa real y del patriarcado jerosolimitano, pues sirvió para elevar el prestigio tanto de la joven dinastía reinante como el de la jerarquía eclesiástica recientemente

l'Occidente nell'arte del XIII secolo", ed. Hans BELTING. Bologna 1983, pp. 55-69: Ben HENDRICKX, Les reliques et objets saimts dans les chroniqeurs français de Constantinople. "Ekklesiastikos Pharos" 72 (1990), pp. 113-126; Jannic DURAND, Reliques et reliquaires arrachés à l'Orient et à Byzance au temps des croisades, "Les Croisades. L'Orient et l'Occident d'Urbain II à Saint Louis 1096-1270“, ed. Monique REY-DELQUÉ, Milano, 1997, pp. 389.

22Con referencias a las fuentes: Frolow, Relique, pp. 286-287; Fulcher de Chartres, Historia Hierosolymitana (1095-1127), ed. Heinrich HAGENMEYER, Heidelberg, 1913, pp. 309310; Peter Plank, Patriarch Symeon II. Von Jerusalem und der erste Kreuzzug. Eine quellenkritische Untersuchung, "Ostkirchliche Studien", 43 (1994), pp. 275-328, especialmente pp. 319-321; Deborah GERISH, The True Cross and the Kings of Jerusalem, "The Haskins Society Journal“" (en prensa), nota 4. Le agradezco a Deborah Gerish su amabilidad de enviarme su artículo antes de su publicación.

${ }^{23}$ Bernard Hamilton, The Latin Church in the Crusader States. The Secular Church, London, 1980, pp. 61-62, 113-115, 129, 151; Jaroslav FoLDA, The Art of the Crusaders in the Holy Land (1098-1187). Cambridge, 1995, pp. 35-36, 49, 78, 82-85, 124, 166-167, 391-392, 487-490; Gerish. True Cross.

${ }^{24}$ Gerish, True Cross; Penny COLE, Christian Perceptions of the Battle of Hattin (5831187), "Al-Masaq" 6 (1993) pp. 9-39, especialmente pp. 12-14, y ahora, con referencias a estudios anteriores: Alan MURRAY, 'Mighty' Against the Enemies of Christ': The Relic of the True Cross in the Armies of the Kingdom of Jerusalem, "The Crusades and Their Sources: Essays Presented to Bernard Hamilton", ed. John FranCE / William ZaJaC, Aldershot, 1998, pp. $217-238$.

${ }^{25}$ Willelmi Tyrensis Archiepiscopi, Chronicon, I-II, Corpus Christianorum, Continuatio Mediaevalis 63, ed. Robert B. C. HuYGENS, Turnhout, 1986, pp. 730-731; Frolow, Relique, p. 289; Murray, Mighty Against the Enemies, pp. 230, 235-236. 
reestablecida ${ }^{26}$. La reliquia fue entregada al patriarca y su cabildo, los canónigos del Santo Sepulcro, convirtiéndoles en los custodes Crucis Domini $^{27}$. Adquirió un lugar de preeminencia dentro de la liturgia jerosolimitana, y la fiesta de su elevación fue celebrada con especial celo ${ }^{28}$. Los patriarcas vigilaron celosamente que su tesoro no corriera riesgos innecesarios, lo cual causó fricciones con el poder secular en varias ocasiones a causa de su negativa a entregarlo al ejercito del reino y acompañarlo en sus campañas $^{29}$. Sin embargo, esta cautela no impidió ni a los patriarcas ni a los canónigos enviar fragmentos de la Vera Cruz a Occidente o entregarlas a peregrinos ${ }^{30}$. No es posible averiguar en cada caso si las astillas procedían del lignum crucis encontrado en 1099, y en varios casos se puede afirmar con seguridad que no fue así. Ya en 1120 se decía que existían más

\footnotetext{
${ }^{26}$ Ligato, Political Meaning; Murray, Mighty Against the Enemies; Gerish, True Cross. Gerish pone en duda que la reliquia haya servido como símbolo de los soberanos del reino.

${ }^{27}$ Le cartulaire du chapitre du Saint-Sépulcre de Jérusalem, Documents relatifs à l'histoire des croisades publiés par l'Académie des Inscriptions et Belles-Lettres 15, ed. Geneviève BRESC-BAUTIER, Paris, 1984, doc. 20,144, 150. Véase también la descripción del tesorero del Santo Sepulcro como "vivifice crucis baiulius" por Guillermo de Tiro (Willelmi Tyrensis Archiepiscopi, Chronicon, p. 1032); Ligato, Political Meaning, p. 326. Según Francesco Tommasi, los templarios hicieron de guardianes armados de la reliquia durante las campañas militares (Francesco TOMMASI, I Templari e il culto delle reliquie, "I Templari: mito e storia". Atti del Convegno internazionale di studi alla Maggione templare di Poggibonsi-Siena, 29-31 Maggio 1987, Sinalunga-Siena, 1989, pp. 191-210, especialmente pp. 195-196).

${ }^{28}$ Peregrinatores tres: Saewulf, John of Würzburg, Theodericus, Corpus Christianorum, Continuatio Mediaevalis 139, ed Robert B.C. HuYGENS, Turnhout, 1994, pp. 123, 153, 167; FoldA, Art of the Crusaders, p. 391. Sobre la importancia litúrgica de la Vera Cruz y sus reliquias después de la pérdida de Jerusalén - por ejemplo durante las procesiones antes de la batalla de las Navas de Tolosa- véase: Amnon LINDER, Individual and Community in the Liturgy of the Liberation of Christian Jerusalem, "Information, Kommunikation und Selbstdarstellung in mittelalterlichen Gemeinden", Schriften des Historischen Kollegs, Kolloquien 40, ed. Alfred HAVERKAMP, München 1998, pp. 25-41, especialmente p. 35; Christoph T. MAIER, Crisis, Liturgy and the Crusade in the Twelfth and Thirteenth Centuries, "Journal of Ecclesiastical History" 48 (1997), pp. 628-657.

${ }^{29} \mathrm{Hans}$ Eberhard MAYER, Jérusalem et Antioche au temps de Baudouin II, "Comptes-rendus de l'Academie des Inscriptions et Belles-Lettres", Novembre-Décembre 1980, Paris, 1980, pp. 717-733; FOLDA, Art of the Crusaders, pp. 82-83; MURRAY, Mighty Against the Enemies, pp. 223-224; GERISH, True Cross.

${ }^{30}$ Sobre el envío de partículos de la Vera Cruz véase: Frolow, Relique, passim; GAUTHIER, Routes de la foi, pp. 47-82; MURRAY, Mighty Against the Enemies, p. 221; FOLDA, Art of the Crusaders, pp. 68, 83, 290, 391, 509; LigATO, Political Meaning, pp. 318, 324; Jonathan RILEY-SMITH, King Fulk of Jerusalem and the 'Sultan of Babylon', "Montjoie: Studies in Crusade History in Honour of Hans Eberhard Mayer", ed. Benjamin Z. KEDAR / Jonathan RILEY-SMITH / Rudolf HiESTAND, Aldershot, 1997, pp. 55-66, especialmente pp. 56-57; THURRE, Reliquaires; DURAND, Reliques et reliquaires, pp. 378-379.
} 
de veinte trozos de la Vera Cruz en Bizancio y Palestina ${ }^{31}$, y su número aumentó constantemente. A veces, los destinatarios de estos regalos eran cabildos o individuos con los que los canonici Sanctissimi Sepulcri o su superior mantuvieron relaciones de amistad, como en el caso del los cabildos de La Mans y París en 1116 y $1120^{32}$, o del mismo Bernardo de Claraval en $1135^{33}$. En algunos casos fueron filiaciones del cabildo en Occidente, es decir prioratos de la Orden del Santo Sepulcro como la casa de Denkendorf en Wurtemberg, cuyo fundador Berthold fue obsequiado con una partícula en $1128^{34}$, o la casa de Barletta en Apulia ${ }^{35}$. Entre los cruzados y peregrinos que volvieron a sus países de origen con una reliquia del lignum crucis cabe destacar Sigurdo, rey de Noruega ${ }^{36}$. Hedwig de Schaffhausen, que

${ }^{31}$ Anselmi cantoris S. Sepulcri epistula ad canonicos ecclesiae Parisensis de Santa Cruce, "Migne, Patrologia Latina", vol. 162, Paris, 1889, c. 729-732, especialmente c. 732. con la corrección de la datación ofrecida por Geneviève BAUTIER, L'Envoie de la relique de la Vraie Croix à Notre-Dame de Paris en 1120, "Bibliothèque de l'Ecole des Chartes" 129 (1971), pp. 387-397.

${ }^{32}$ Le Mans: Actus pontificum Cenomannis in urbe degentium, "Archives historiques du Maine 2“, ed. G. BUSSON / A. LEDRU, Le Mans, 1901, pp. 431-432. Paris: Anselmi cantori, Cartulaire général de Paris, I (528-1180), ed. Robert DE LASTEYRIE, Paris, 1887, pp. 171-174; FRolow, Relique, pp. 310-311; BAUTIER, L'Envoie de la relique. La reliquia había sido adquirida de la viuda del rey de Georgia por un canónigo del Santo Sepulcro.

${ }^{33}$ Sancti Bernardi opera VII: Epistolae I, ed. Jean LECLERCQ/ Henri RoCHAIS, Roma, 1974, doc. 175, p. 393; Frolow, Relique, p. 323. Véase también la leyenda sobre el envío de una astilla de la Vera Cruz a Messines por el patriarca de Jerusalén Guillermo de Messines: Guy OURY, Guillaume de Messines l'eremite de Fontaines-les-Blanches devenu Patriarche de Jérusalem, "Bulletin de la Société archéologique de Touraine" 37 (1973), pp. 225-243, especialmente pp. 226, 243. En la segunda mitad del siglo, una estauroteca similar fue enviado al sur del Alemania por el patriarca (Wittelsbach und Bayern I/2: Die Zeit der frühen Herzöge von Otto I. zu Ludwig dem Bayern, München-Zürich, 1980, pp. 34-36).

${ }^{34}$ Rolf DeusChLE/ Herbert RAISCH, Kloster Denkendorf und sein Stifter Berthold Graf von Hohenberg/Lichtenfels, "Esslinger Studien", 20 (1981), pp. 7-35; Kaspar ELM, St. Pelagius in Denkendorf. Die älteste deutsche Propstei des Kapitels vom Hlg. Grab in Geschichte und Geschichtsschreibung, "Landesgeschichte und Geistesgeschichte. Festschrift für Otto Herding zum 65. Geburtstag". Veröffentlichungen der Kommission für geschichtliche Landeskunde in Baden-Württemberg B, 92, ed. Kaspar ELM / Eberhard GöNNER / Eugen HILLENBRAND, Stuttgart, 1977, pp. 80-130; FoldA, Art of the Crusaders, pp. 97-100.

${ }^{35}$ Angelo AmBrosi, Architettura dei crociati in Puglia. Il Santo Sepolcro di Barletta, Quaderni dell'Istituto di disegno. Facoltà di Ingegneria, Univerità di Bari 2, Bari, 1976; Nicola U. Gallo, La croce patriarcale della Basilica del S. Sepolcro di Barletta, Archivio di Barletta 6, Barletta 1982, pp. 99-107.

${ }^{36}$ Paul RIANT, Expéditions et pèlerinages des Scandinaves en Terre Sainte au temps des Croisades, Paris, 1865, pp. 188-190; FroLow, Relique, pp. 309-310. 
afirmó haberla recibido de manos del último patriarca griego de Jerusalén ${ }^{37}$, y los duques Leopoldo VI de Austria y Enrique el León ${ }^{38}$. También los soberanos y barones de los estados cruzados, los reyes Balduino I, Fulco, y Amalrico de Jerusalén así como la reina Sibila y varios de los altos dignatarios del reino, enviaron fragmentos de la Vera Cruz a algunos monasterios $^{39}$, y Amalrico obsequió a Enrique II de Inglaterra con otra reliquia en $1173^{40}$.

Pero la historia de la Vera Cruz como símbolo del reino cruzado de Jerusalén acabó de golpe el día 4 de Julio de 1187. En la derrota desastrosa de Hattín, la crux vivifice quedó en el campo de batalla junto con el cuerpo sin vida de su portador -el obispo de Acre- y de la mayor parte del ejercito del reino de Jerusalén ${ }^{41}$. A pesar de los intentos diplomáticos por recuperarla, y a pesar de las leyendas cristianas que lo negaron, la reliquia jerosolimitana del lignum crucis desapareció para siempre ${ }^{42}$. Sin embargo, esta pérdida no significó el fin de la producción y de la circulación de reliquias o relicarios de la Vera Cruz. La insignia del reino de Jerusalén tan

\footnotetext{
${ }^{37}$ Monachi anonymi Scaphensis, De reliquiis Sanctissimae Crucis et Dominici Sepulchri Scaphusam allatis, "Recueil des Historiens des Croisades. Historiens Occidentaux", V, Paris, 1895, pp. 335-339; Plank, Patriarch Symeon II., pp. 315-319.

${ }^{38}$ Auctarium Sancrucense, "MGH SS“, vol. IX, Hannover, 1851, p, 732; Die Urkunden Heinrichs des Löwen, Herzogs von Sachsen und Bayern, "MGH Laienfürsten und Dynastenurkunden der Kaiserzeit", 2 vols., ed. Karl JORDAN, Stuttgart, 1941, I, doc. 94, 95; Hans Eberhard MAYER, Die Stiftung Herzog Heinrichs des Löwen für das Hl. Grab, "Heinrich der Löwe". Veröffentlichungen der Niedersächsischen Archivverwaltung 39, ed. Wolf-Dieter MohrmanN, Göttingen, 1980, pp. 307-330; Heinrich der Löwe und seine Zeit. Herrschaft und Repräsentation der Welfen 1125-1235, Katalog der Ausstellung, Braunschweig, 1995, ed. Jochen LUCHHARDT/ Franz NIEHOFF, München, 1995, pp 276-281; Johannes FRIED, Jerusalemfahrt und Kulturimport. Offene Fragen zum Kreuzzug Heinrichs des Löwen, "Der Welfenschatz und sein Umkreis“, ed. Joachim EHLERS/ Dietrich KöTZSCHE, Mainz, 1988, pp. 111-139, especialmente pp. 113-114. Otros ejemplos: Frolow, Relique, pp. 308, 317, 319, 324-326, $329,344,345,347,349$.

${ }^{39}$ Annales Corbeienses, "MGH SS“, vol. III, Hannover, 1839, pp. 2-18, especialmente p. 7; Actus pontificum Cenomannis, p. 430; Frolow, Relique, pp. 320-322, 338, 344, Hans Eberhard MAYER, Das Pontifikale von Tyrus und die Krönung der lateinischen Könige von Jerusalem, "Dumbarton Oaks Papers", 21 (1967), pp. 141-232, especialmente p. 182, nota 185; Gauthier, Routes de la foi, pp. 56-58.

${ }^{40}$ Reinhold RÖHRICHT, Die Geschichte des Königreichs Jerusalem (1100-1291), Innsbruck, 1898 , p. 358.

${ }^{41}$ Cole, Christian Perceptions of the Battle of Hattin.

${ }^{42}$ Sobre la supuesta historia posterior de la Vera Cruz: Frolow, Relique, pp. 69-72, 347 348; Tommasi, Templari e il culto, p. 195; Ligato, Political Meaning, pp. 315-316; PierreVincent Claverie, Un cas de trafic de reliques dans le royaume de Jérusalem au XIII s.: L'affaire 'Giovanni Romano', "Revue historique de droit française et étranger", 75 (1997), pp. 627-637.
} 
sólo había consistido en la parte de la Vera Cruz encontrada en 1099, otras partículas ya estaban en poder de instituciones cristianas de Tierra Santa o llegaron allí traídas por los mismos cruzados. El ejército principal de la primera cruzada ya disponía de astillas del lignum crucis antes de conquistar la Ciudad Santa, y sabemos que los cruzados ingleses que salieron para Palestina durante la Segunda Cruzada llevaban una reliquia similar cuando tomaron Lisboa en $1148^{43}$. Así pues, tanto en Outremer como en este lado del Mediterráneo quedó un número elevado de reliquias y estaurotecas. La Vera Creu d'Anglesola es tan sólo una de ellas, un miembro poco conocido de una gran familia.

Debido a su origen en Tierra Santa o Bizancio, muchas estaurotecas medievales formaron parte de la gran circulación de reliquias y relicarios, “... la triangulation de l'espace maritime et continental où circulèrent les reliquaires, leurs contenus, leurs collectionneurs, leurs auteurs et leurs fabriquants" ${ }^{44}$. En este contexto, los relicarios sirvieron como un vehículo no poco importante de la comunicación medieval ${ }^{45}$. En cambio, a un nivel

\footnotetext{
${ }^{43}$ Ligato, Political Meanings, p. 319, nota 15; OSBERnUs, De expugnatione Lyxbonensi, ed. Charles W. DAvidS, Records of Civilisation 24, New York 1936, pp. 146, 154-156. Sobre la participación de los cruzados en la lucha contra musulmanes en la Península Ibérica: Nikolas JASPERT, 'Capta est Dertosa, clavis Christianorum': Tortosa and the Crusades, "The Second Crusade. Scope and Consequences“, ed. Martin HocH/ Jonathan PHILLIPS, Manchester, 1999 (en prensa)

${ }^{44}$ GAUTHIER, Reliquaires du XIII" siècle, p. 56

${ }^{45}$ Renate Kroos, Vom Umgang mit Reliquien, "Ornamenta ecclesiae. Kunst und Künstler der Romanik“, 3 vols., ed. Anton LEGNER, Köln, 1985, III, pp. 25-49; Horst WENZEL, Hören und Sehen, Schrift und Bild. Kultur und Gedächtnis im Mittelalter, München, 1995, pp. 95-115. En general sobre la comunicación medieval véase: Sophia MENACHE, The Vox Dei. Communication in the Middle Ages, New York-Oxford, 1990; Kommunikation und Alltag in Spätmittelalter und früher Neuzeit, Sitzungsberichte der Österreichischen Akademie der Wissenschaften, Phil.-Hist. Klasse 596, Wien, 1992; La circulation des nouvelles au mojen âge, XXIVe Congrès de la S.H.M.E.S. Avignon, juin 1993, Roma, 1994; Kommunikation zwischen Orient und Okzident. Alltag und Sachkultur, Österreichische Akademie der Wissenschaften. Phil.-Hist. Klasse, Sitzungsberichte 619, Wien, 1994; Kommunikation und Mobilität im Mittelalter. Begegnungen zwischen dem Süden und der Mitte Europas (11.-14. Jh.), ed. Siegfried W. DE RaChEwILtz/ Josef Riedmann. Sigmaringen, 1995; David Crowley, La comunicación en la historia: tecnología, cultura, sociedad, Barcelona, 1997; Gert ALTHOFF, Zur Bedeutung symbolischer Kommunikation für das Verständnis des Mittelalters, "Frühmittelalterliche Studien“ 31 (1997), pp. 370-389. Sobre la obras artísticas entre los estados cruzados y Occidente véase: Bianca KüHNEL, L'art des croisades entre L'Orient et l'Occident, "Les
} 
local, tanto las reliquias como sus receptáculos fueron puntos de cristalización de la devoción popular. Estaurotecas como la de Anglesola tuvieron una forma característica que los contemporáneos asociaron con Jerusalén. Estas mostraban una relación directa y fácilmente identificable con su contenido - hasta el punto que se las puede calificar de relicarios parlantes. Justamente la visualización de la reliquia garantizaba una mejor participación de la virtus y presentia de la misma. Por ello, la devoción religiosa, las memorias y las emociones colectivas se concentraron tanto en las reliquias como en sus contenedores, convirtiéndolos así en un elemento importante de cohesión social $^{46}$

Considerando su importancia tanto para la historia del arte como para la historia religiosa y social, no sorprende que las estaurotecas hayan generado algunos, aunque no muchos, estudios monográficos. Hace más de tres décadas, Anatole Frolow presentó un estudio exhaustivo de La relique de la Vraie Croix, donde aportó gran cantidad de referencias sobre reliquias perdidas o existentes. Este trabajo sirve todavía hoy día de base imprescindible para cualquier investigador del tema. Tanto la Vera Creu de Bagà como la de Oviedo están incluidas ${ }^{47}$. Pero la Vera Creu d'Anglesola, les santes virtuts, no aparece en su obra. Este hecho por sí solo justifica un estudio más detallado de la pieza, sobre todo porque aún no se sabe de la misma otra cosa que vaya más allá de las leyendas locales.

Para situar la Vera Creu d'Anglesola en este amplio contexto y apreciarla en lo justo, es preciso aclarar tanto su origen como la fecha de su fabricación. Hasta ahora, los estudiosos no han presentado ninguna interpretación o hipótesis. En cambio, un estudio comparativo de la Vera Creu d'Anglesola con otros relicarios contemporáneos mostrará que ésta no sólo señala hacia Jerusalén, sino que efectivamente fue fabricada en la Ciudad Santa en la segunda mitad del siglo XII.

Croisades. L'Orient et l'Occident d'Urbain II à Saint Louis 1096-1270“, ed. Monique ReYDELQUÉ, Milano, 1997, pp. 341-353.

${ }^{46} \mathrm{Hans}$ BelTing, Die Reaktion der Kunst des 13. Jahrhunderts auf den Import von Reliquien und Ikonen, "Ornamenta ecclesiae. Kunst und Künstler der Romanik", 3 vols., ed. Anton LEGNER, Köln, 1985, III, pp. 173-183, especialmente p. 176; Patrick H. HUTTON, Collective Memory and Collective Mentalities. The Halbwachs-Ariès Connection, "Historical Reflections/ Reflexions Historiques“, 15 (1988), pp. 311-322, especialmente p. 316; WENZEL, Hớren und Sehen, pp. 99-102.

${ }^{47}$ Frolow, Relique, pp. 277-278, 363. 
En un artículo corto, pero de gran envergadura científica escrito hace más de veinte años, Heribert Meurer logró identificar dos grupos de estaurotecas de origen jerosolimitano ${ }^{48}$. Basándose tanto en documentación contemporánea como en argumentos estilísticos, supo demostrar que talleres de orfebrería existieron en la Ciudad Santa desde la tercera década del siglo XII, donde se fabricaron relicarios de la Vera $\mathrm{Cruz}^{49}$. Probablemente los artesanos dependieron de - o por lo menos colaboraron con- la iglesia del Santo Sepulcro y su superior, el patriarca, en cuya cercanía inmediata tuvieron sus talleres ${ }^{50}$. Un primer grupo de estaurotecas fue fabricado alrededor del año 1130. Sus piezas más importantes son dos, enviadas en su día a prioratos de la Orden del Santo Sepulcro en Denkendorf (Wurtemberg) y Barletta (Apulia) respectivamente. Se caracterizan por la gran diferencia entre verso y anverso: éste lleva medallas estampadas con las figuras del Tetramorfos en el travesaño inferior, el cordero dentro de otro medallón en el nudo inferior, con ornamentos vegetales cubriendo el vástago vertical y los travesaños. El verso en cambio lleva una gran ranura en forma de cruz patriarcal con astillas de lignum crucis, bordado de rosetas en el exterior del vástago y de los travesaños y un gran número de piedras engastadas. El segundo grupo está relacionado con el primero, pero muestra una ejecución menos fina y un programa iconográfico más completo en el anverso. Según Meurer, este grupo abarca cinco piezas; sin embargo, a mi modo de ver dos de ellas forman un grupo propio ${ }^{51}$, dejando un tercero de solo tres estaurotecas. Son las cruces de Santiago de Compostela (Museo de la Catedral, fig. 5 y 6$)^{52}$, París (Museo del Louvre, fig. 7 y 8$)^{53}$ y Agrigento (Museo

\footnotetext{
${ }^{48}$ Heribert MEURER, $\mathrm{Zu}$ den Staurotheken der Kreuzfahrer, "Zeitschrift für Kunstgeschichte“, 48 (1985), pp. 65-76. Véase también: Heribert MEURER, Kreuzreliquiare aus Jerusalem, "Jahrbuch der Staatlichen Kunstsammlungen in Baden-Württemberg", 13 (1976), pp. 7-17.

${ }^{49}$ MeURER, Staurotheken, p. 74

${ }^{50}$ Como ha puesto de relieve Folda, Art of the Crusaders, pp. 99-100.

${ }^{51}$ Son las cruces de Conques (Abadía de Sainte Foy) y Kaisheim (Augsburg, Städtische Kunstsammlung). Se diferencian del tercer grupo en que ambas están adornadas con piedras engastadas, no llevan ni el Tetramorfos ni medallones con plantas en su anverso, y su representación del Santo Sepulcro es de una forma totalmente diferente del tercer grupo.

${ }^{52}$ Galicia Arte, vol. 10: arte medieval 1, A Coruña, 1993, pp. 487-488; Serafín Moralejo Álvarez, Lignum Crucis de Carboeiro, "Santiago, camiño de Europa. Culto y cultura en la peregrinación a Compostela“, Santiago de Compostela, 1993, pp. 352-353; La Catedral de Santiago de Compostela, Patrimonio Artístico Gallego 1, La Coruña, 1993, pp. 512-514; Nikolas JASPERT, "Pro nobis, qui pro vobis oramus, orate": die Kathedralskapitel von Compostela und Jerusalem in der ersten Hälfte des 12. Jahrhunderts, "Santiago, Roma,
} 
Nacional, fig. 4) ${ }^{54}$. Las cuatro piezas no son idénticas, pero sí de una semejanza sorprendente: sus anversos están bordadas por una línea perlada, llevan las figuras del Tetramorfos acogidas por medallones en los extremos del palo vertical y en los travesaños, con el águila de San Juan en la parte superior, el toro de San Lucas a la izquierda, el león de San Marcos a la derecha y el ángel de San Mateo en la parte inferior. Tienen dos ranuras en los nudos para las astillas de la Vera Cruz, rosetas ciegas y círculos con variadas hojas. Su elemento más característico se ubica en la parte inferior del palo vertical: es una estampa de un lucillo de medio punto que se eleva sobre dos columnas, coronado por una cruz. Entre la columnas cuelga una lámpara, y debajo de ella se distingue un banco con tres óculos abiertos. Sin duda alguna se trata de una representación del Santo Sepulcro. Descripciones del mismo de comienzos del siglo XII ya mencionan el mármol que estaba fijado delante del banco pétreo del Sepulcro. Estaba perforado por tres agujeros para que los peregrinos pudieran ver o tocar la piedra sagrada. Representaciones parecidas del Santo Sepulcro se encuentran en los sellos del patriarca y de la orden de San Juan de Jerusalén ${ }^{55}$.

Basándose en Meurer, autores posteriores han datado el segundo grupo de estaurotecas por los años $1170^{56}$. Para ello toman como referencia la supuesta refundación del monasterio de Carboeiro en 1170, desde el cual el relicario gallego llegó a la catedral de Santiago de Compostela. Sin duda, este argumento no es suficiente para fijar la fecha de fabricación en 1170 ,

Jerusalén“. III Congreso Internacional de Estudios Jacobeos, Santiago de Compostela 14-16 septiembre 1997, ed. Paolo CaUCCI von SAUCKEN, Santiago de Compostela, 1999, pp. 7-27. El relicario Compostelano tampoco figura en la obra de FROLOW (Relique).

${ }^{53}$ The Glory of Byzantium. Art and Culture of the Middle Byzantine Era, A.D. 843-1261, ed. Helen C. Evans/ William D. WIXOM, New York, 1997, pp. 398-399, fig. 264.

${ }^{54}$ Maria ACCASCINA, Oreficeria di Sicilia dal XII all XIX secolo, Palermo, 1976; pp. 66-70, fig 35; Marie-Madeleine GAUTHIER, Emaux meridionaux I. Catalogue international de l'oeuvre de Limoges, Paris 1987, p. 57.

${ }^{55}$ Véase la descripción de Theodericus de los años sesenta del siglo XII: "Quod Pario marmore, auro et lapidibus preciosis mirifice decoratum tria in latere rotunda habet foramina, per que ipsi lapidi, in quo dominus iacuit, optata peregrini porrigunt oscula..." (Peregrinatores tres: Saewulf, John of Würzvurg, Theodericus, ed. Robert B.C. HUYGENS, Corpus Christianorum, Continuatio Mediaevalis 139, Turnhout, 1994, p. 148). Liselotte KÖTZSCHE, Zwei Jerusalemer Pilgerampullen aus der Kreuzfahrerzeit, "Zeitschrift für Kunstgeschichte" ", 51 (1988), pp. 13-32, especialmente pp. 25-26, fig. 16, 18, 19; KüHNEL, Crusader Art, pp. 143145; FOLDA, Art of the Crusaders, p. 294.

${ }^{56}$ FoldA, Art of the Crusaders, p. 581, nota 240. Meurer mismo se expresó de una manera más cautelosa. 
ni para la estauroteca de Compostela, ni para los otros miembros del grupo. Pero aún así es posible averiguar fechas post et ante quem: representaciones muy parecidas a las de las estaurotecas se encuentran en ampollas de peregrinos que Liselotte Kötzsche ha datado convincentemente en la segunda mitad del siglo XII ${ }^{57}$, pues la cúpula que se alza encima del sepulcro no es otra que la cúpula de la Iglesia del Santo Sepulcro tal como quedó después de la reconsagración por los cruzados en 1149. Parece que también las estaurotecas fueron fabricadas después de esta reconsagración. Es lícito fijar como fecha ante quem tanto de las ampollas como de los relicarios la pérdida de la Ciudad Santa y del lignum crucis en 1187.

En su artículo, Heribert Meurer expresó la esperanza de que se encontraran otras estaurotecas con características parecidas a las que el había identificado: "Ich rechne damit, daß weitere Kreuze dieser Art gefunden werden" 58 . Efectivamente, ahora se puede añadir un cuarto ejemplar a este grupo, la Vera Creu d'Anglesola. No cabe la más mínima duda de que fue fabricado en el mismo lugar, incluso con las mismas herramientas, que las cruces de Santiago, París y Agrigento. A pesar del estado algo deteriorado de la obra y los mediocres intentos de restauración así como las añadiduras posteriores, queda lo suficiente de la estructura original para percatarse de ello. Los elementos ornamentales, la técnica y las características iconográficas son casi idénticas. Tan sólo la mano de Dios y la paloma en el dorso de la Vera Creu d'Anglesola no se encuentran en ninguna de las otras piezas ${ }^{59}$. Las similitudes con la estauroteca de Agrigento son especialmente notables: hasta la inusual colocación del Tetromorfos alrededor del nudo superior se repite, en ambas piezas se encuentran los ángeles que señalan hacia el centro. También reaparece la figura barbuda orando con las manos en alto al pie de la cruz. Ocupa el lugar tradicionalmente reservado para representaciones del donante. Aquí sin embargo, su función parece otra: con su aspecto exótico recordaba a los observadores el origen lejano de la reliquia y la reverencia debida a la misma, exhortándoles a seguir su ejemplo

\footnotetext{
${ }^{57}$ KöTZSCHE, Zwei Jerusalemer Pilgerampullen, pp. 17-18. Cf. la ilustración en: Heinrich der Löwe und seine Zeit, pp. 281-282, fig. D86.

${ }^{58}$ MEURER, Staurotheken, p. 76.

${ }^{59} \mathrm{Cabe}$ considerar, sín embargo, que no disponemos del dorso de la estauroteca de Agrigento, la más similar a la catalana.
} 
adorando la Vera $\mathrm{Cruz}^{60}$. Las cuatro obras son de una técnica bastante sencilla, lo que da soporte a la hipótesis de que fueron producciones rápidas y regulares dedicadas a la exportación. La cruz Compostelana es la única que todavía mantiene intacto su pie, una bola achatada con un fuste troncocónico que permitía colocarla encima de una palo ${ }^{61}$. Posiblemente, las otras cruces tenían la misma construcción, que se puede observar en las estaurotecas - también de origen jerosolimitano- de Scheyern, Barletta, Conques, y Cleveland. Daba una mayor movilidad a la reliquia y permitía llevarla en auténticas campañas limosneras para pedir donativos para el sustento y la defensa de los estados cruzados ${ }^{62}$. Documentos contemporáneos dan testimonio de la utilización de las estaurotecas tanto para estos fines como de cruz de procesión ${ }^{63}$. La Creu de Santa Anna de Barcelona por ejemplo tuvo una gran importancia para las fiestas y procesiones de la Ciudad Condal ${ }^{64}$. Se puede suponer que la estauroteca de Anglesola tuvo una finalidad parecida. Desgraciadamente no hay manera de datar convincentemente las ahora cinco estaurotecas de este grupo, pero sus características técnicas - de influencia bizantina - y tanto tipológicas como iconográficas - de raíces más bien occidentales ${ }^{65}$ - no dejan lugar a dudas de que fueron fabricadas de manera seriada, dentro de un marco cronológico muy reducido.

\footnotetext{
${ }^{60}$ Véase por ejemplo el caso de la cruz relicaria de Borghorst de la segunda mitad del siglo XI - también con partículas del lignum domini (Das erste Jahrtausend. Kultur und Kunst in werdenden Abendland an Rhein und Ruhr, 2 vols. ed. Victor H. ELBERN, Düsseldorf, 1962, II, p. 85, fig. 392 y 393). Gracias al profesor Elbern por haber llamado mi atención a la cruz de Borghorst. Sobre la función del orante cf. Hans BelTING, Das Bild und sein Publikum im Mittelalter. Form und Funktion früher Bildtafeln der Passion, Berlin, 1981, pp. 69-104.

${ }^{61}$ Peter SPRINGER, Kreuzfüße. Ikonographie und Typologie eines hochmittelalterlichen Gerätes, Bronzegeräte des Mittelalters 3, Berlin, 1981, pp. 22-24, fig. A1, A10-13, A16-18, A26-31.

${ }^{62}$ Pierre André SIGAL, Les voyages de reliques aux XIe et XIIe siècles, "Voyage. quête, pèlerinage dans la littérature et la civilisation médiévales". Aix-en-Provence - Paris, 1976, pp. 75-104; Edina Bozoky, Voyages de reliques et démonstration du pouvoir aux temps féodaux, "Voyages et voyageurs au Moyen Age", Série Histoire Ancienne et Médiévale 39, Paris, 1996, pp. 267-281. Sobre la crítica contemporánea a prácticas similares: Reinhold KaISER, Quêtes itinerantes avec des reliques pour financer la construction des églises, XI'XII" siècles, "Le Moyen Age“ 101 (1995), pp. 205-225.

${ }^{63}$ Véase el ejemplo de la estauroteca de Scheyern, enviada al sur de Alemania en relación con una de las campañas mencionadas: Wittelsbach und Bayern, pp. 34-36.

${ }^{64}$ Barcelona, Arxiu Diocesà de Barcelona, Fons de Santa Anna, RD-2, fol. 44r (1383). Llibre de solemnitats de Barcelona I (1429-1546), ed. Antoni DURAN I SANPERE/ José SANABRE, Barcelona, 1930, pp. 17, 148-149.

${ }^{6.5} \mathrm{Como}$ ha puesto de relieve Bianca Kühnel (KüHnel, Crusader Art, pp. 148-153).
} 
Una vez establecida la procedencia de la Vera Creu d'Anglesola, quedan por esclarecer las circunstancias que la llevaron a Cataluña. Es posible, pero más bien improbable que haya llegado a la Segarra portada por un peregrino, tal como dice la leyenda local. Es menester buscar individuos o instituciones locales que mantuvieron vínculos de algún tipo con los estados cruzados en general y Jerusalén en particular. Como punto de partida se imponen los señores mismos de la villa, el linaje de los Anglesola.

Desde los tiempos de Berenguer Gombau, un fidelis de Ramón Berenguer II y Berenguer Ramón II, la familia de los Anglesola experimentó un ascenso vertiginoso debido a su proximidad a la familias condales de Barcelona y Urgell. Junto con los Cervera, Jorba, Torroja y otras familias del Urgell, de la Segarra y la Anoia se convirtieron en unos de los "barons nous mes importants de Catalunya"66. A pesar de fricciones ocasionales con sus señores ${ }^{67}$, los Anglesola mantuvieron esta posición durante casi un siglo. Como otros linajes pujantes del siglo XII, los Anglesola se orientaron hacia las nuevas formas de vida religiosa de su tiempo ${ }^{68}$. Fueron de los primeros en fomentar activamente la joven Orden del Císter en Cataluna, vinculándose con especial intensidad a las abadías de Vallbona de les Monges y Poblet ${ }^{69}$. También los canónigos regulares de San Agustín, en concreto las casas de Bellpuig de les Avellanes y de Santa María de Solsona, gozaron de su respaldo ${ }^{70}$. No sorprende entonces que existieran relaciones amistosas entre la familia y las nuevas instituciones de Tierra Santa. Cuando

\footnotetext{
${ }^{66}$ Els castells catalans, V, ed. Pere CATALÀ I Roca, Barcelona, 1979, p. 975. Sobre la familia véase ibidem, pp. 974-983; BACH, Història d'Anglesola, pp. 31-41; BINEFA, El senyoriu d'Anglesola.

${ }^{67}$ Flocel SABATÉ I CURULL, Judici entre el comte Ramon Berenguer IV i Bernat d'Anglesola, "Ilerda“, 49 (1991), pp. 129-142.

${ }^{68}$ Otros ejemplos en: JASPERT, Stift und Stadt, pp. 250-277.

${ }^{69}$ Agustí ALTISENT, Poblet, Bernat d'Anglesola i dues expedicions militars d'Alfons el Cast (València $i$ Tolosa), "Miscellanea Populetana", Scriptorium Populeti, 1, Abadía de Poblet, 1966, pp. 155-185; BInEFA, Anglesola, pp. 15-17; BInEFA, Senyoriu d'Anglesola, pp. 38-45; $\mathrm{BACH}$, Anglesola, pp. 34-35.

${ }^{70} \mathrm{BACH}$, Anglesola, p. 33-34; Josep TORRES I GROS, Guillem d'Anglesola, baró de Bellpuig, fundador del monestir de Bellpuig de les Avellanes i del monestir de Sant Nicolau, a Bellpuig. Bellpuig, 1987.
} 
los primeros milites Templi llegaron a Cataluña a comienzos de la tercera década del siglo XII, Arnau Berenguer fue de los primeros en darles su apoyo $^{71}$, y sus sucesores siguieron esta línea hasta entrado el siglo XIII ${ }^{72}$. Pero los templarios no eran los únicos religiosos de Tierra Santa que podían contar con los Anglesola. También los canónigos del Santo Sepulcro fueron protegidos por la familia, hecho inadvertido hasta la fecha.

El 21 de Junio de 1154, Berenguer Arnau d'Anglesola, sus hijos Berenguer y Bernat así como Arnau Berenguer d'Anglesola junto con sus hijos - también ellos de nombre Berenguer y Bernat - hicieron donación de la mitad de la torre de Carassumada cerca de Torres del Segre a la Orden del Santo Sepulcro ${ }^{73}$. Por las mismas fechas, Arnau Berenguer cedió unas casas en Anglesola a la misma orden, y a finales del siglo, Berenguer d'Anglesola complementó estas donaciones con otra de bienes, entre ellas casas, cerca de Anglesola y dentro del pueblo mismo ${ }^{74}$. Ya los primeros obsequios fueron de tal importancia que quedaron reflejados en la lista de posesiones de la orden incluida en la bula Si apostolice sedis de $1164^{75}$. Cuando el priorato barcelonés de Santa Anna comenzó a extender su área de influencia a otras zonas catalanas, los bienes en el Urgell, la Anoia y la Segarra fueron de las primeras que cayeron bajo su control ${ }^{76}$. Los

\footnotetext{
${ }^{71}$ Col-lecció diplomàtica de la casa del Temple de Barberà, Textos Jurídics Catalans, Documents 1, ed. Josep Maria SANS I TRAVÉ, Barcelona, 1997, doc. 28; Nikolas JASPERT, Die Ritterorden und der Orden vom Heiligen Grab auf der Iberischen Halbinsel, "Militia Sancti Sepulcri. Idea e Istituzioni. Colloquio Internazionale, Pontificia Università del Laterano, 10-12 aprile 1996“, ed. Kaspar ELM / Cosimo Damiano FONSECA, Hierosolimitana. Acta et Monumenta 1, Città del Vaticano, 1998, pp. 381-410.

${ }^{72 B I N E F A, ~ S e n y o r i u ~ d ' A n g l e s o l a, ~ p p . ~ 45-46 ; ~ P r i m ~ B E R T R A N ~ I ~ R o I g E ́, ~ N o t i c i e s ~ h i s t o ̀ r i q u e s ~ d e l ~}$ Palau d'Anglesola (segles XII-XVII), Publicacions de I'Institut d'Estudis Ilerdencs 45, Lleida, 1981, pp. 17-19, 51-63.

${ }^{73}$ Jesus Alturo I Perucho, L'arxiu antic de Santa Anna de Barcelona del 942 al 1200. Aproximació històrico-lingüística. 3 vols. . Fundació Noguera. Textos i Documents 8-10. Barcelona, 1985, II, doc. 290

${ }^{74}$ Alturo, L'arxiu antic de Santa Anna, III, doc. 567; Barcelona, Arxiu Diocesà, Fons de Santa Anna (en los sucesivo: ADB-SA), Pergamins, carpeta 8, doc. 146. Donación adicional en Anglesola por Valentí en 1199 (Alturo, L'arxiu antic de Santa Anna, III, doc. 633) y Pons Metge con su esposa Agnes antes de 1202 (ADB-SA, Pergamins, carpeta 8, doc. 53).

75 “... domos et terras in Anglarola et in eius territorio ..." (Papsturkunden für Kirchen im Heiligen Land, Vorarbeiten zum Oriens Pontificius 3, ed. Rudolf HIESTAND, Göttingen, 1985, doc. 88.)

${ }^{76}$ Ya en 1191 expresó sus exigencias al respecto: ALTURO, L'arxiu antic de Santa Anna, III, doc. 566. Véase en general: Nikolas JASPERT, La estructuración de las primeras posesiones del Capitulo del Santo Sepulcro en la Península Ibérica: La génesis del priorato de Santa Anna en Barcelona y sus dependencias, "La Orden del Santo Sepulcro. Primeras jornadas de estudio,
} 
canónigos debieron ejercer su autoridad con cierto éxito, pues pronto la calle donde tuvieron casas y talleres fue conocida como "carraria de Sepulcro"77. Una noticia de 1244 tiene especial relevancia en nuestro contexto: según la misma, los canónigos habrían erigido una capilla propia en su calle ${ }^{78}$.

Sabemos que varias de las estaurotecas de origen jerosolimitano llegaron a Europa a través de la orden del Santo Sepulcro. Tanto el relicario de Denkendorf como el de Barletta pertenecieron a sendos prioratos de la misma ${ }^{79}$. En otros casos no se puede determinar con seguridad si la existencia de algún relicario se debió a los canónigos, ya que la procedencia de la mayoría de las estaurotecas queda sin aclararse. Pero cabe recordar que tanto la estauroteca de Agrigento como la de París - que se supone proviene del sur de Italia ${ }^{80}$ - señalan hacia áreas donde la orden tuvo un número de filiaciones especialmente elevado ${ }^{81}$. Los grandes prioratos de la orden solían disponer de varias reliquias de Tierra Santa, y sus inventarios demuestran que tanto las reliquias de la Vera Cruz como las del Santo Sepulcro tuvieron un lugar de preeminencia entre las mismas: sabemos por ejemplo que ambos prioratos catalanes de la orden, el de Santa Anna de Barcelona y el de Marcévol, dispusieron de reliquias de la Vera $\mathrm{Cruz}^{82}$. Hasta la pieza Compostelana puede haber llegado a San Lorenzo de Carboeiro, desde donde fue trasladada a Compostela, a través de una dependencia de la orden del Santo Sepulcro: es sabido que una dependencia de San Lorenzo de Carboeiro

Calatayud-Zaragoza, 2-5 abril 1991“. Madrid, 1991, pp. 93-108.

${ }^{77}$ ADB-SA, Pergamins, carpeta 27, doc. 13.

${ }^{78}$ ADB-SA, Pergamins, carpeta 2, doc. 448.

${ }^{79}$ Véase arriba, notas 34 y 35

${ }^{80}$ Glory of Byzantium, pp. 398-399; Frolow, Reliquaires, p. 127.

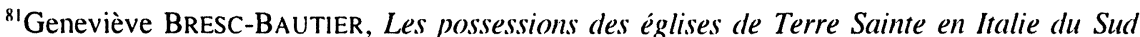
(Pouille, Calabre, Sicile), "Roberto il Guiscardo e il suo tempo". Pubblicazioni del Centro di Studi Normanno-Svevi. Università degli Studi di Bari 1. Roma. 1975, pp. 13-34; La Puglia fra Bizancio e l'Occidente, ed. Cosimo Damiano FonsECA, Civiltà e cultura in Puglia 2, Milano, 1980; Valentino PACE, Italy and the Holy Land, Import-Export 2: The Case of Apulia, "Crusader Art in the Twelfth Century“, ed. Jaroslav FoldA, Oxford, 1982, pp. 245-269; KüHNEL, Crusader Art, pp. 147-148.

${ }^{82} \mathrm{ADB}-\mathrm{SA}, \mathrm{O}-1$, Inventari, fol. $1^{\mathrm{r}}-2^{\mathrm{r}}$; Jean SARRETE, Le pardon de Marcevol, Perpignan 1902, p. 8. Sobre estaurotecas posteriores (siglos XV-XX) de la Orden del Santo Sepulcro véase: Amelia LóPEZ-YARTo Elizalde, Orfebrería de la Orden del Santo Sepulcro: Cruces procesionales y cruces relicarios. "La Orden del Santo Sepulcro. Actas de las Segundas Jornadas de Estudio, Zaragoza, 23-26 noviembre de 1995", Zaragoza, 1996, pp. 327-340. Véase las noticias sobre reliquias y relicarios de la Vera Cruz en la Orden del Temple: TOMmaSI, Templari e il culto, pp. 196-210. 
- se trata del monasterio de San Vicente de Nogueira- pasó a convertirse en una casa de la orden del Santo Sepulcro ${ }^{83}$. La existencia de una estauroteca jerosolimitana en Anglesola, un pueblo donde la orden del Santo Sepulcro dispuso de muchas posesiones y hasta de una capilla, se enmarca nítidamente en esta tendencia. Parece verosímil que la Vera Creu d'Anglesola no fuera llevada al Urgell por un peregrino, sino por los mismos canónigos jerosolimitanos. De esta manera, la orden del Santo Sepulcro, al igual que muchas otras órdenes supranacionales, figuró como vehículo de comunicación internacional ${ }^{84}$.

Queda por explicar como la estauroteca acabó en la iglesia parroquial. Tan sólo se puede señalar una hipótesis al respecto. Desde comienzos del siglo XIII, los canónigos mantuvieron su presencia en la villa mediante un procurador. Ya en 1200 los cónyuges Arsenda y Portal recibieron este cargo vitalicio, y Guillem Portal lo heredó de sus padres en $1237^{85}$. Estos procuradores obtuvieron ingresos y prestigio a cambio de sus servicios en favor de la casa de Santa Anna, servicios que incluyeron el cobro de las rentas de la orden en la región y la obligación de dar acogida a los fratres de la orden que llegaban a la villa. De esta manera, los canónigos que estaban de camino al segundo centro de la orden en la Corona catalano-aragonesa, el priorato de Calatayud, tenían un lugar de descanso

\footnotetext{
${ }^{83}$ Hipólito de SA Y Bravo, El monacato en Galicia, 2 vols., La Coruña, 1972, II, 211-216. Limitado a los aspectos artísticos: Ramón YzQUIERDO, El monasterio de Carboeiro, "Monacato gallego. Sexquimilenario de San Bieito. Actes do primeiro coloquio, Ourense 1981", Boletín Auriense, Anexo 6, Ourense, 1986, pp. 121-153; Galicia Arte, I, pp. 254-256; Galicia Arte, vol. 11: arte medieval 2, A Coruña 1996, pp. 170-177. Sobre las filiaciones gallegas de la Orden del Santo Sepulcro: JASPERT, "Pro nobis, qui pro vobis oramus, orate". Esta explicación parece más verosimil que la leyenda local, que atribuye la Vera Cruz de Carboeiro al arzobispo Guy de Vienne, después Papa Calixto II (La Catedral de Santiago de Compostela, p. 514).

${ }^{84}$ Hartmut Boockmann. Der Deutsche Orden in der Kommunikation zwischen Nord und Süd, "Kommunikation und Mobilität im Mittelalter", pp. 179-190: Jörg OBERSTE. Institutionalisierte Kommunikation. Normen, Überlieferungsbefunde und Grenzbereiche im Verwaltungsalltag religiöser Orden des hohen Mittelalters, "De ordine vitae. Zu Normvorstellungen, Organisationsformen und Schriftgebrauch im mittelalterlichen Ordenswesen“. ed. Gert MELVILLE, Vita Regularis 1, Münster, 1996, pp. 59-99; Jörg OBERSTE, Visitation und Ordensorganisation. Formen sozialer Normierung, Kontrolle und Kommunikation bei Cisterziensern, Prämonstratensern und Cluniazensern (12.-frühes 14. Jh.), Vita Regularis 2, Münster, 1996; Nikolas JASPERT, Centro y periferia. Los superiores de la Orden del Santo Sepulcro y sus prioratos en la Corona catalano-aragonesa, "La Orden del Santo Sepulcro. Actas de las Segundas Jornadas de Estudio, Zaragoza, 23-26 noviembre de 1995“, Zaragoza, 1996, pp. 125-139. 41 .

${ }^{85}$ Alturo, L'arxiu antic de Santa Anna, III, doc. 638; ADB-SA, Pergamins, carpeta 2, doc.
} 
durante el viaje ${ }^{86}$. Pero la sucesibilidad del cargo y la distancia hasta la casa madre en Barcelona crearon fuerzas centrífugas, y Guillem Portal intentó usurpar las posesiones de la orden. Encontró un aliado potente en Guillem d'Anglesola. Casi un siglo después de sus primeros donativos, el apoyo inicial de la familia hacia la orden del Santo Sepulcro había desaparecido. Se produjeron conflictos abiertos entre los Anglesola y Guillem Portal por una parte y los canónigos por otra, que tan sólo acabaron cuando los papas Gregorio IX e Inocencio IV mandaron infligir penas eclesiásticas a la parte rebelde $^{87}$. Parece que en el transcurso de este conflicto quedó destruida la capilla, pues en 1244 el nuevo procurador del Santo Sepulcro prometió reedificarla ${ }^{88}$.

Durante siglos, los canónigos todavía dispusieron de sus posesiones en la villa, donde tuvieron más de veinte enfiteúticos y varios operatoria, según un caputbreve de $1260^{89}$. Los priores de Santa Anna siguieron instituyendo procuradores hasta mediados del siglo $\mathrm{XIV}^{90}$. Pero a pesar de la promesa de 1244, no volvemos a tener noticias de la capilla del Sepulcro. Es de suponer que la estauroteca de Anglesola perteneció a esta capilla perdida de la Orden del Santo Sepulcro, que o no fue reedificada nunca después de su destrucción en el siglo XIII o bien fue abandonada cuando la casa madre de Santa Anna cortó los últimos vínculos con el pueblo durante el siglo XIV. El hecho de que las primeras noticias documentales sobre el altar dedicado a la Vera Cruz en la iglesia parroquial y sobre la reliquia misma daten de la segunda mitad del siglo XIV, da soporte añadido a esta hipótesis. Con el tiempo, la memoria de la presencia de los canónigos jerosolimitanos en Anglesola desapareció, las calles cambiaron de nombre, las operatoria del Sepulcre perdieron el suyo. Tan sólo quedó una única huella de una historia muy remota: la Vera Creu d'Anglesola, un vestigio de Tierra Santa en Cataluña.

\footnotetext{
${ }^{86}$ Sobre el papel de los prioratos como centros administrativos de su provincia véase JASPERT, Centro y periferia.

${ }^{87}$ ADB-SA, Pergamins, carpeta 8, doc. 146; ADB-SA, CD-0, doc. 8, 51 y 82.

${ }^{88}$ ADB-SA, Pergamins, carpeta 2, doc. 448.

${ }^{89}$ ADB-SA, Pergamins, carpeta 1 , doc. 15.

${ }^{90}$ ADB-SA, Pergamins, carpeta 2, doc. 448; carpeta 2, doc. 165; carpeta 28, doc. 3; carpeta 2 , doc. 221 ; carpeta 2 , doc. 247 ; carpeta 2 , doc. 348 . El último procurador conocido fue Guillem Mercader, en 1348: ibidem, carpeta 1-7, doc. 42. En 1342 todavía hay noticias sobre un taller "del Sepulcre" (ADB-SA, Pergamins, carpeta 2, doc. 51).
} 


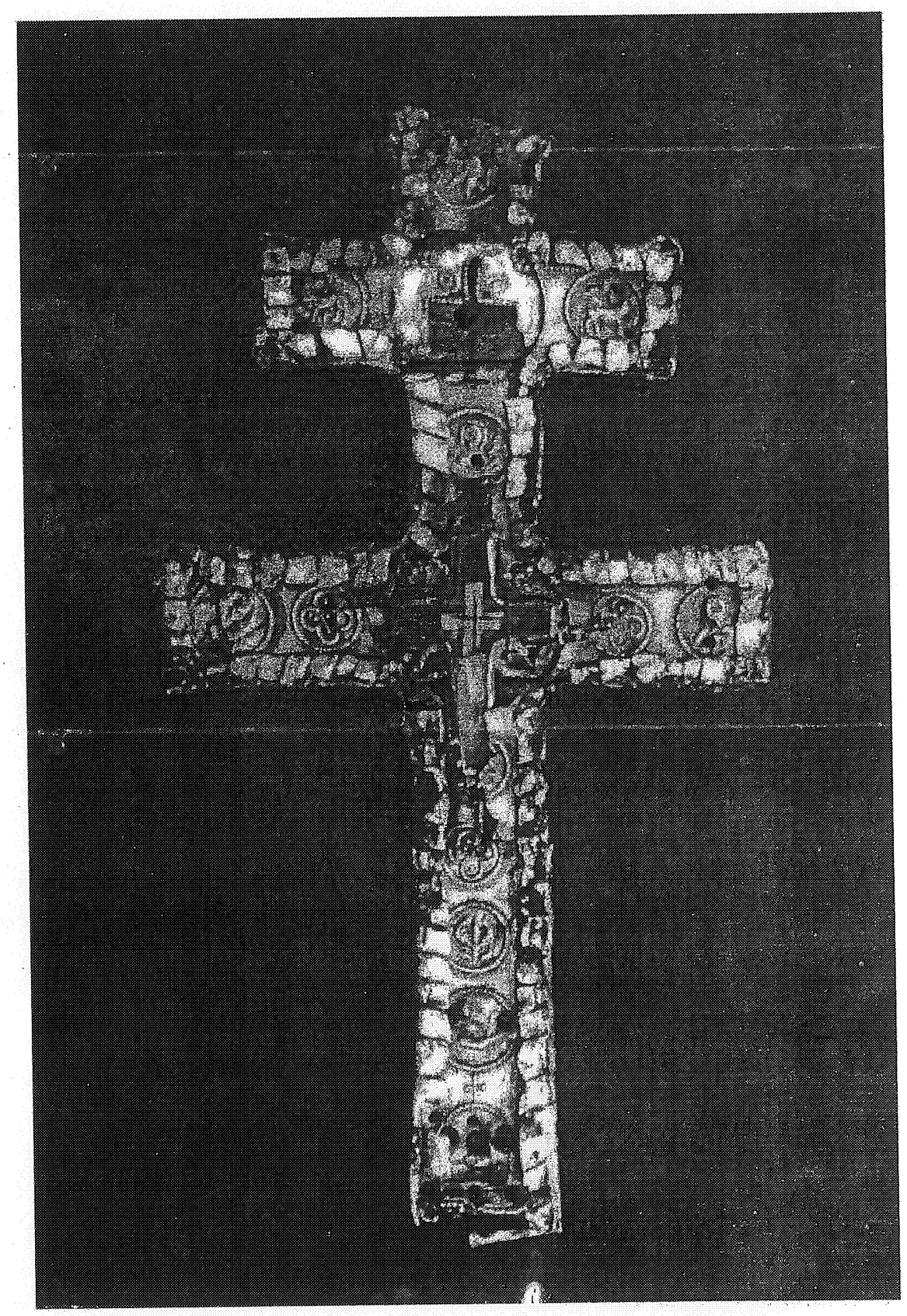

Fig. 1. Anglesola, Iglesia parroquial: La Vera Creu d'Anglesola, verso, estado actual (fotografía: autor/Mn. Prat). 


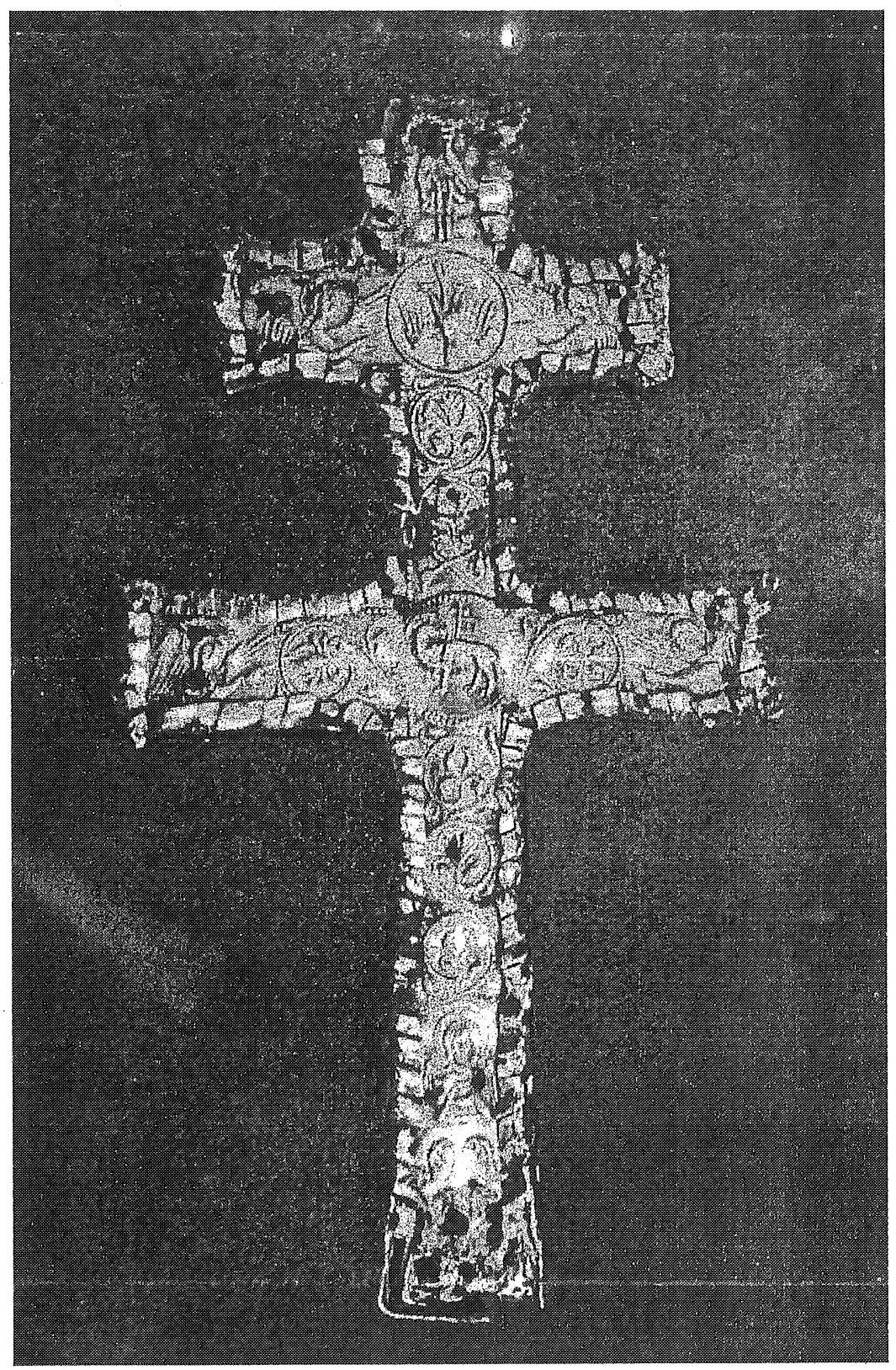

Fig. 2. Anglesola, Iglesia parroquial: La Vera Creu d'Anglesola, anverso, estado actual (fotografía: autor/Mn. Prat). 


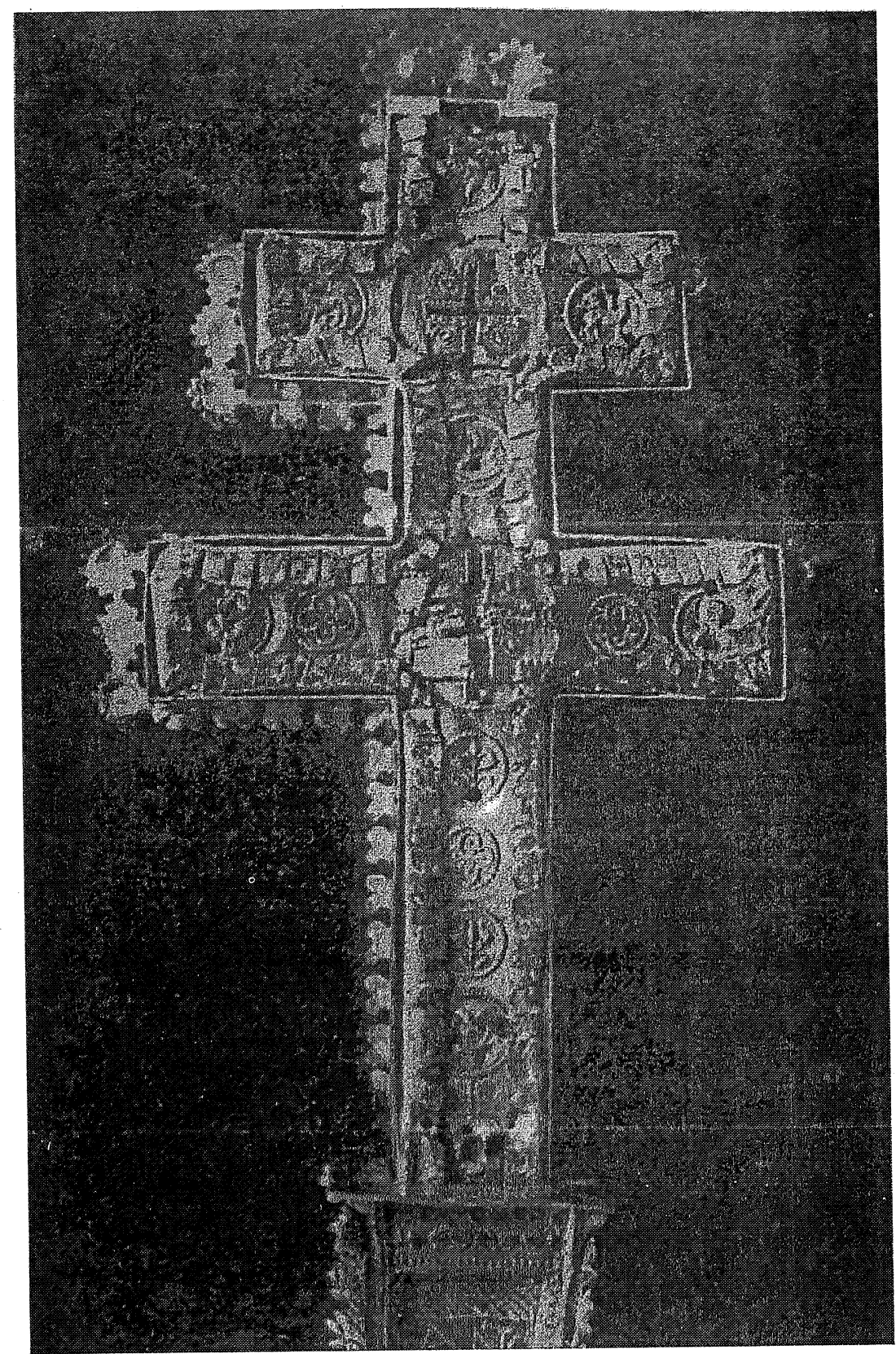

Fig. 3. Anglesola, Iglesia parroquial: La Vera Creu d'Anglesola, anverso, 1921 (fotografía: Institut Amatller, Barcelona). 


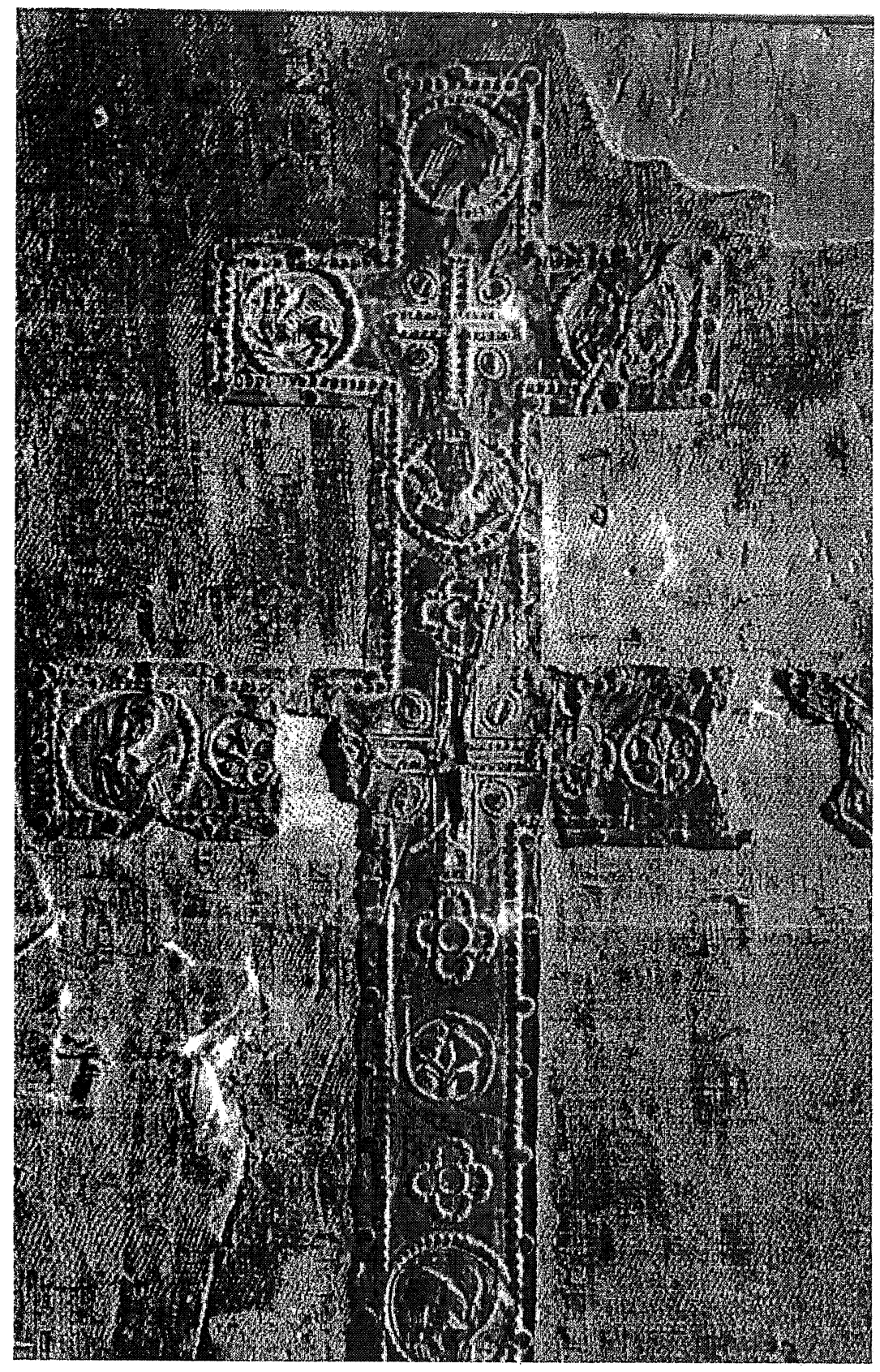

Fig. 4. Agrigento, Museo Nazionale: altar portátil, verso (fotografía: Gabinetto nazionale di fotografia, Roma, $N$ 1119). 


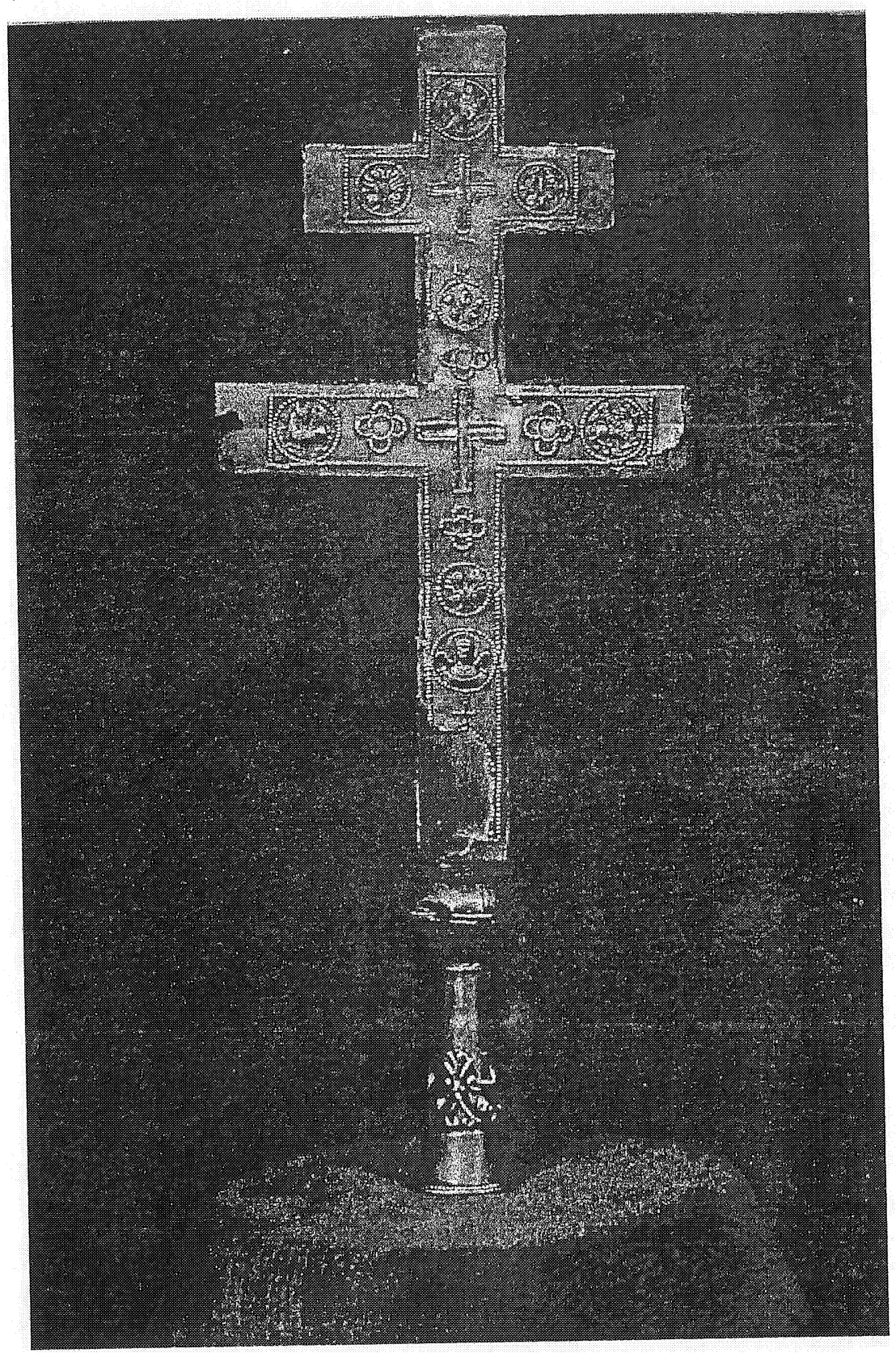

Fig. 5. Santiago de Compostela, Museo de la Catedral: Cruz de Carboeiro, anverso. 


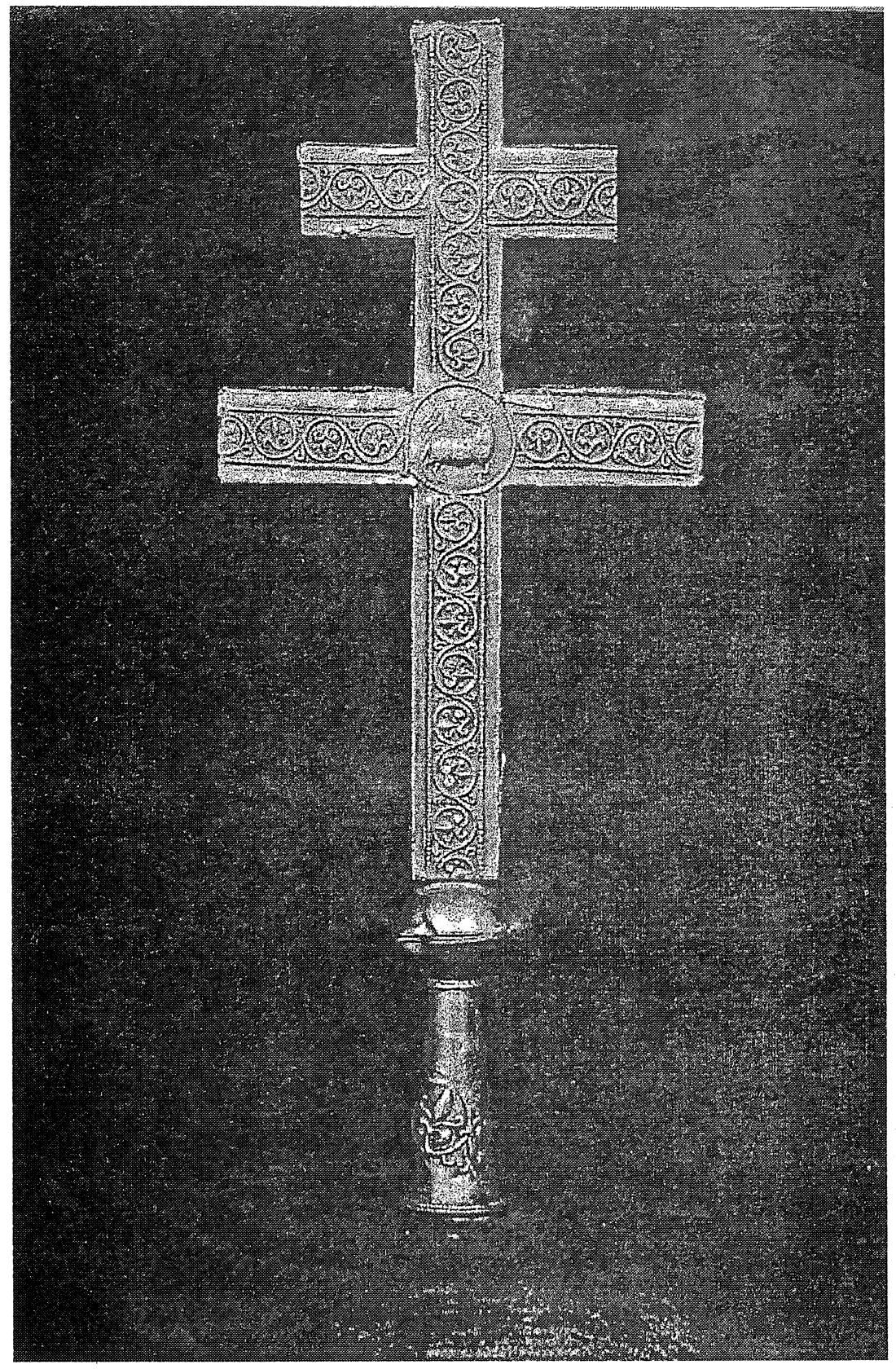

Fig. 6. Santiago de Compostela. Museo de la Catedral: Cruz de Carboeiro, verso. 


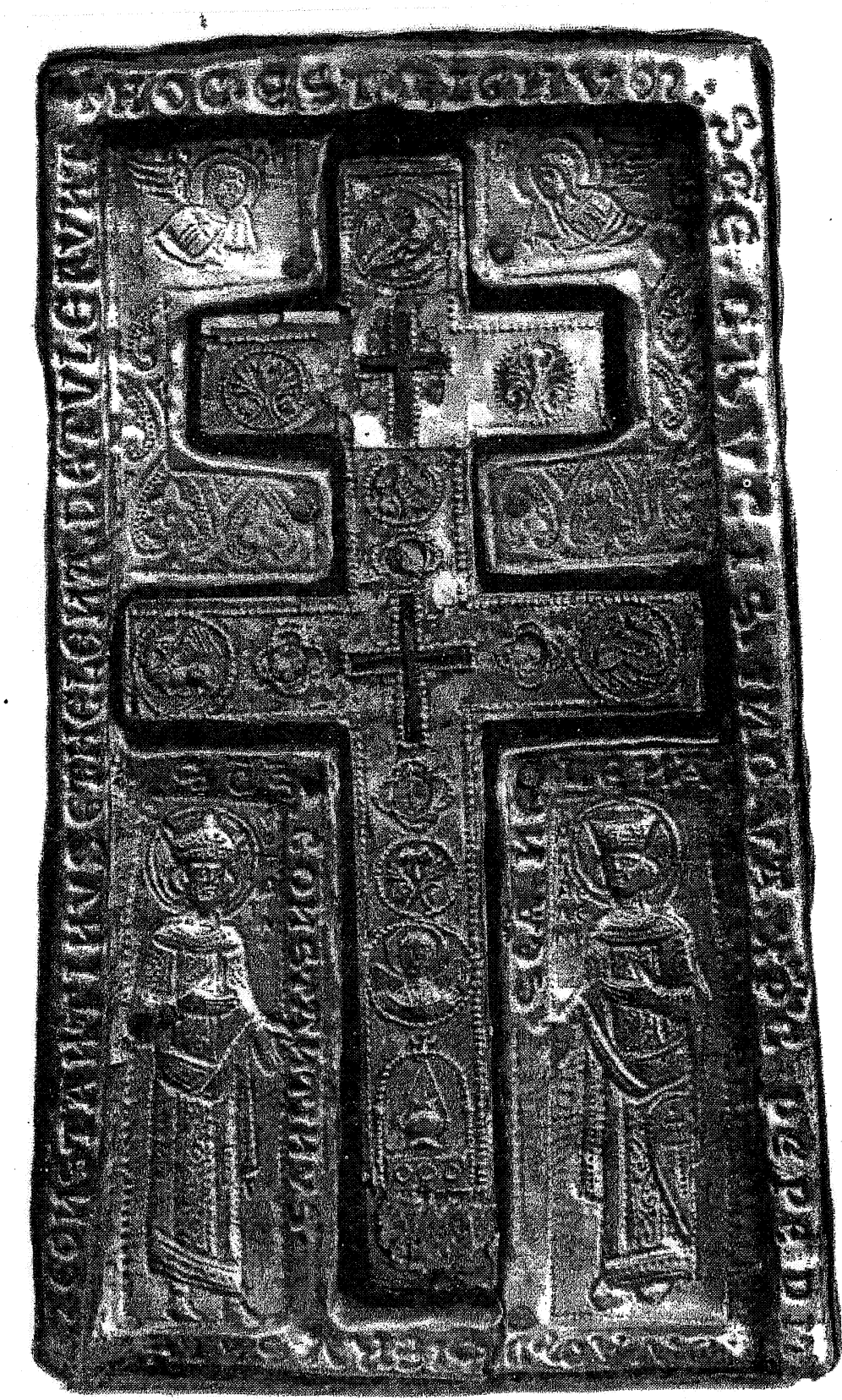

Fig. 7. Paris. Musée du Louvre. Département des Objets d’Art, nºA 3665: estauroteca, anverso (fotografía: Musée du Louvre). 


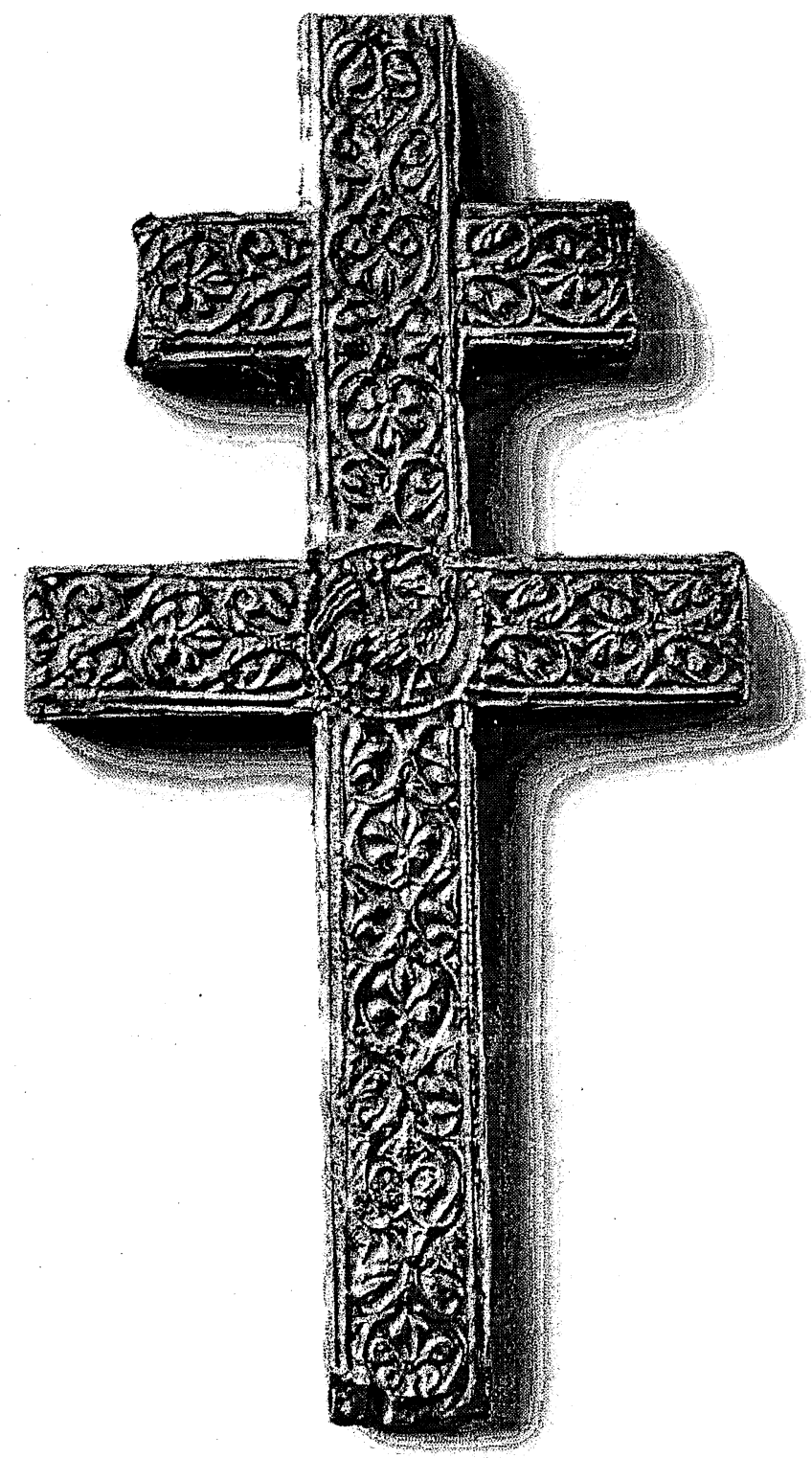

Fig. 8. Paris, Musée du Louvre, Département des Objets d'Art, n OA 3665: estauroteca, verso (fotografía: Musée du Louvre). 


\section{RÉSUMÉ}

Une relique de la Vraie Croix est conservée dans l'église paroissiale d'Anglesola en Catalogne occidentale. Son origine n'a pas été clairement retracée à ce jour. Une étude comparée de trois staurothèques semblables et de la Vera Creu d'Anglesola démontre que celle-ci serait issue de Jérusalem lors de la deuxième moitié du XII ${ }^{\mathrm{e}}$ siècle. L'auteur estime que la relique a été apportée en Catalogne par les chanoines du Saint Sépulcre. Il est prouvé que ceux-ci possédaient une maison et une chapelle à Anglesola et que celles-ci furent abandonnées peu avant les premiers témoignages évoquant la présence de la relique dans l'église paroissiale.

\section{SUMMARY}

The parish church of Anglesola in western Catalonia houses a reliquiary of the True Cross, the origins of which have hitherto not been determined. A comparison between three similar cross-reliquiaries and the Vera Creu d'Anglesola proves that the latter was produced in Jerusalem in the second of the twelfth century. The article argues that the cross reached Catalonia via the canons of the Holy Sepulcre, who were not fostered by local nobles but also held a house and a chapel in Anglesola, which was given up shortly before the reliquiary is first mentioned in the records of the parish church. 